\title{
Effect of thoracic irradiation on hepatocyte growth factor in rats lung and in bronchoalveolar lavage fluid of patients with thoracic malignancies
}

\author{
H. Yamazaki*, E. Takeuchi+, J.T. Tang*, S. Fukushima*, Ta. Inoue*, K. Shinkawa ${ }^{+}$ \\ Y. Watanabe ${ }^{+}$, E. Tanaka**, T. Teshima**, S. Ozeki*, M. Koizumi*, M. Ito ${ }^{+}$, \\ H. Nakamura**, To. Inoue*
}

\begin{abstract}
Effect of thoracic irradiation on hepatocyte growth factor in rats lung and in bronchoalveolar lavage fluid of patients with thoracic malignancies. H. Yamazaki, E. Takeuchi, J.T. Tang, S. Fukushima, Ta. Inoue, K. Shinkawa, Y. Watanabe, E. Tanaka, T. Teshima, S. Ozeki, M. Koizumi, M. Ito, H. Nakamura, To. Inoue. (C)ERS Journals Ltd 1997.

ABSTRACT: This study aimed to examine the physiological role of hepatocyte growth factor (HGF) after thoracic irradiation.

We analysed the changes of HGF protein levels in rat lung following $12 \mathrm{~Gy}$ of whole thoracic irradiation. Bronchoalveolar lavage fluid (BALF) was then collected from 11 patients (10 lung cancer and one oesophageal cancer) after completion of radiation therapy.

One month after irradiation, the HGF protein level in the lungs of irradiated rats decreased $(p<0.05)$, followed by a remarkable elevation in HGF protein levels $2(p<0.05)$ and 3 months (nonsignificant) after irradiation accompanied by the clinical appearance of radiation pneumonitis. Finally, HGF protein levels in the lung returned to their original level 6 months after thoracic irradiation. In humans, HGF protein levels in the BALF in the limited irradiated area were lower than those obtained from unirradiated areas $(p<0.05)$.

In conclusion, hepatocyte growth factor production is transiently suppressed in the irradiated area after irradiation.
\end{abstract}

Eur Respir J 1997; 10: 2539-2544.
*Dept of Radiation Oncology Biomedical Research Center, and **Dept of Radiology, Osaka University Medical School, Osaka, Japan. +Dept of Medicine, Toneyama National Hospital, Osaka, Japan.

Correspondence: H. Yamazaki

Dept of Radiation Oncology Biomedical Research Center

Osaka University Medical School

2-2 Yamadaoka

Suita

Osaka 565

Japan

Keywords: Hepatocyte growth factor, radiation pneumonitis, rat

Received January 201997

Accepted after revision August 81997

Supported in part by a Research Grant for Science and Cancer from the Ministry of Education, Science and Culture of Japan.
Hepatocyte growth factor (HGF), a putative hepatotropic factor for liver regeneration, was first purified to homogeneity from rat platelets [1] and in plasma [2, 3]. HGF is a heterodimer molecule composed of a $69 \mathrm{kDa}$ $\alpha$-chain and a $34 \mathrm{kDa} \beta$-chain, and contains four kringle domains [4, 5]. HGF is expressed in nonparenchymal cells such as Kupffer cells, sinusoidal cells and Ito cells $[6,7]$ and acts in a paracrine fashion. HGF acts on various epithelial cells including mature hepatocytes and renal tubular cells [8].

HGF activity in the rat liver markedly increases after hepatotoxin induced hepatitis, hepatic ischaemia or other hepatic insults [9-11], and intravenously injected recombinant HGF markedly enhances liver regeneration in mice [12]. The concentration of HGF in peripheral blood was found to rise after partial resection of normal liver both in patients and experimental animals [13], while patients with hepatic failure following hepatectomy showed significantly higher serum HGF levels $[14,15]$. Likewise, a slight increase in serum HGF levels in patients with hepatitis, chronic hepatitis, and liver cirrhosis was noted [16]. HGF may also have a role in regeneration of the kidney after injury [17-19]. In animal experiments, HGF manifested a protective function against the onset of renal dysfunction caused by mer- curic chloride, cisplatinium and ischaemic injury. Recently, some authors reported that HGF may also play an important role in lung injury and subsequent regeneration, i.e. HGF messenger ribonucleic acid (mRNA) and blood HGF activity were markedly induced and exogeneously and intravenously administered HGF enhanced regeneration of epithelial cells in the trachea after $\mathrm{HCl}$ injection [20-22].

It is well known that radiation causes pneumonia and subsequent fibrosis in the lung, but little is known about the relationship between HGF and radiationinduced lung injury. For this reason, we have developed a rapid and sensitive enzyme-linked immunosorbent assay (ELISA) for measurement of HGF levels in rat crude tissue extract [23]. We used this technique to analyse changes in tissue and plasma HGF protein levels in rat after exposure to whole thoracic irradiation. We also analyzed bronchoalveolar lavage fluid (BALF) in 10 patients with lung cancer and one with oesophageal cancer after completion of radiation therapy. To detect physiological changes in the irradiated area, we took BALF from both the irradiated field and control unirradiated area. The number of cells, percentage of lymphocytes, concentrations of protein, albumin and aminoterminal peptide of type III precollagen (PIIIP), 
CD4, CD8 and CD25 ratios and interleukin (IL)-6 and HGF concentrations were analysed. HGF concentration in blood samples was also examined in these patients.

\section{Materials and methods}

\section{Animals}

Adult male Wistar rats weighing 180-200 g were used for the experiments. The animals were given food and water ad libitum. After being anaesthetized, the rats were fixed in a supine position on a plastic plate, and 12 Grays (Gy) of whole thoracic irradiation was administered with the aid of a designated lead collimator to assure that both lungs were in the field. An X-ray generator Radiflex 350 (180 kV, 150 mA; Rigaku Electronics Co., Tokyo, Japan) was used. Similarly handled sham-irradiated animals served as controls. Irradiated rats and age-matched controls were killed at appropriate intervals.

\section{Preparation of rat lung tissue extract and plasma}

Lungs were removed and the lung tissues homogenized in 4 volumes.g tissue ${ }^{-1}$ of buffer composed of 10 $\mathrm{mM}$ Tris- $\mathrm{HCl}$ (pH 7.5), $2 \mathrm{M} \mathrm{NaCl}, 1 \mathrm{mM}$ phenymethyl sulphonyl fluoride (PMSF), $1 \mathrm{mM}$ ethylenediamine tetraacetic acid (EDTA), 0.01\% Tween 80. The homogenate was centrifuged at $105,000 \times \mathrm{g}$ for $1 \mathrm{~h}$ and the resultant supernatant was used as a crude tissue extract. Plasma was collected from the rat aorta using citric acid as an anticoagulant agent, and centrifuged at $10,000 \times \mathrm{g}$. The supernatant was then removed to serve as plasma samples, which were partially purified with heparinSepharose beads. These tissue extracts and plasma samples were stored at $-70^{\circ} \mathrm{C}$ until assay.

\section{ELISA}

Details of the ELISA system have been described elsewhere [23]. Briefly, $50 \mu \mathrm{L}$ of monoclonal antibody to rat HGF $\left(20 \mu \mathrm{L} \cdot \mathrm{mL}^{-1}\right.$ immunoglobulin $(\mathrm{Ig})-\mathrm{G}$ in 50 $\mathrm{mM}$ sodium bicarbonate buffer) was added to 96 well microtitre plates followed by incubation for $8 \mathrm{~h}$ at room temperature. One hundred microlitres of a blocking agent composed of phosphate buffered saline (PBS) containing 5\% rabbit serum was added and the preparation incubated overnight at $4^{\circ} \mathrm{C}$. The wells were then washed three times with PBS-Tween and standard HGF and test samples were added to duplicate wells and incubated for $2 \mathrm{~h}$ at room temperature. After the wells had been washed three times with PBS-Tween, the second biotinated antibody (anti-rat HGF polyclonal antibody) was added followed by incubation for $1.5 \mathrm{~h}$ at room temperature. After another washing with PBS-Tween, a horse radish peroxidase conjugated streptavidin-biotin complex diluted with PBS containing $0.5 \%$ bovine serum albumin (BSA) and $0.05 \%$ Tween 20 was added and the preparation incubated for $1.5 \mathrm{~h}$ at room temperature. After a final washing with PBS-Tween, a chromogenic substrate solution $(2.5 \mathrm{mg}$ o-phenylenediamine, $0.5 \mathrm{M}$ sodium phosphate and $0.1 \mathrm{M}$ citric acid with $\mathrm{pH}$ 5.0) was added, the enzyme reaction was halted with $1.5 \mathrm{~N} \mathrm{H}_{2} \mathrm{SO}_{4}$, and absorbance at $490 \mathrm{~nm}$ was measured.

\section{Patients and processing of BALF}

BALF was obtained from the 11 patients $1-10$ days after completion of limited thoracic irradiation to the lung and oesophageal cancers. Patient characteristics are shown in table 1 . Treatment conditions for lung cancer have been described in detail elsewhere [24]. A total irradiation dose of 50-64 Gy was delivered with a daily dose of 2 Gy administered for 5 days week $^{-1}$. Radiation was administered with a $10 \mathrm{MV}$ linear accelerator. The patients consisted of eight males and three females with an age range 47-79 yrs (mean 66 yrs). Bronchoalveolar lavage (BAL) was performed on a segment in the irradiated field and one in the nonirradiated area as a control. None of the patients showed signs of infection or haemorrhage in the lower respiratory tract. Sterile physiological saline was infused and aspirated, after which the aspirated fluid was strained through gauze and immediately centrifuged gently to separate cellular and noncellular fractions. We used $100 \mathrm{~mL}$ of physiological saline to wash each part of lung (irradiated and nonirradiated). Almost half of this could be recovered for analysis. Ten millilitres of each sample was used to detect concentration of HGF. A few millilitres aliquot of recovered BALF was used for other examinations. The cellular fraction was utilized to analyse the cell count (total cell count, percentage of macrophages, lymphocytes, eosinophils, neutrophils, CD4, CD8, CD4/CD8

Table 1. - Patients characteristics and treatment

\begin{tabular}{cccccccc}
\hline $\begin{array}{c}\text { Patient } \\
\text { No. }\end{array}$ & Sex & $\begin{array}{c}\text { Age } \\
\text { yrs }\end{array}$ & $\begin{array}{c}\text { Tumour } \\
\text { category }\end{array}$ & Stage & Chemotherapy & Histology & $\begin{array}{c}\text { Irradiated dose } \\
\text { Gy }\end{array}$ \\
\hline 1 & M & 76 & Oes & & CDDP, VDS & SQ & 60 \\
2 & M & 70 & T4N2M1 & 4 & CDDP, VDS & SQ & 50 \\
3 & F & 59 & T3N3M1 & 4 & CDDP, VDS, MMC & AD & 50 \\
4 & M & 70 & T2N2M1 & 4 & CARB & SQ & 54 \\
5 & M & 79 & T4N3M0 & $3 B$ & CDDP, VDS & SQ & 62 \\
6 & M & 68 & T4N2M1 & 4 & CDDP, VDS, MMC & AD & 64 \\
7 & F & 47 & T3N2MX & $3 B$ & CDDP, VDS, MMC & AD & 56 \\
8 & M & 65 & T2N3M1 & 4 & CDDP, VDS, MMC & SQ & 50 \\
9 & M & 73 & T2N2M1 & 4 & CDDP, VDS & AD & 50 \\
10 & M & 64 & T4N2M0 & $3 B$ & CDDP, VDS, MMC & SQ & 50 \\
11 & F & 65 & T4N2M1 & 4 & CDDP, VDS & AD & 50
\end{tabular}

M: male; F: female; Oes: oesophageal cancer; CDDP: cisplatinium; VDS: vindecine; SQ: squamous cell carcinoma; MMC: mitomicin; AD: adenoimatous carcinoma; CARB: carboplatineum. 
ratio, CD25). The total cell count was performed with a haemocytometer, and the differential cell count on slide preparations of cells stained with May-Grunwald Giemsa. CD4, CD8 and CD25 cells were detected by flowcytometry with a fluorescein isothiocyanate (FITC) labelled antibody for each of the cell types (Ortho Diagnostic Systems, Inc. Raritan, New Jersey, USA). A noncellular fraction was utilized for assay for protein, albumin and (PIIIP) and IL-6. Protein and albumin concentrations were analysed with the aid of a Micro TPtest kit (Wako Pure Pharmaceuticals, Osaka, Japan) and a latex agglutination test with LX reagent (Eiken Pharmacy, Tokyo, Japan), respectively. The aminoterminal peptide of type III precollagen (PIIIP) was analysed using a radioimmunoassay with a monoclonal antibody to PIIIP (radioimmunoassay (RIA)-gnost PIIIP coated tube; Hoechst Japan, Tokyo, Japan). IL-6 was examined with ELISA (Fuji Rebio, Tokyo, Japan). After quadruple dialysis with exchanged distilled water overnight, the concentration of the BALF was increased 20 times by freeze drying. HGF was measured using an ELISA kit for human HGF (Institute of Immunology Co., Tokyo, Japan), and the lower limit of detection was set at 0.1 $\mathrm{ng} \cdot \mathrm{mL}^{-1}$. All patients gave their informed consent in writing with regard to both the purpose and protocol of the study.

\section{Analysis of blood HGF concentration}

Serum HGF levels were examined in these patients before and after radiation therapy. The blood was allowed to clot, after which the serum was separated by centrifugation at 1,500 revolutions per minute (rpm), and stored at $-70^{\circ} \mathrm{C}$ until the assay. Serum HGF was measured by using an ELISA kit for human HGF (Institute of Immunology Co., Tokyo, Japan), and the lower limit of detection was set at $0.1 \mathrm{ng} \cdot \mathrm{mL}^{-1}$.

\section{Assessment of radiation pneumonitis}

Chest radiographs were used every month to assess lung injury from completion of the treatment until 12 months later. When abnormal shadows appeared, computed tomography (CT) images were used to identify conditions other than radiation pneumonitis, such as recurrence [24]. We defined the clinical symptoms of radiation pneumonitis as dyspnoea, chest pain, cough and fever concurrent with abnormal shadows on the CT images.

\section{Statistical analysis}

Student's t-test for two sets of data and analysis of variance (ANOVA) for multiple sets were used, and a p-value of less than 0.05 was considered significant. Data are presented as mean \pm SD.

\section{Results}

\section{Changes in HGF protein levels in rats}

Changes in HGF protein levels in the lung are depicted in figure 1 . The HGF protein level in normal

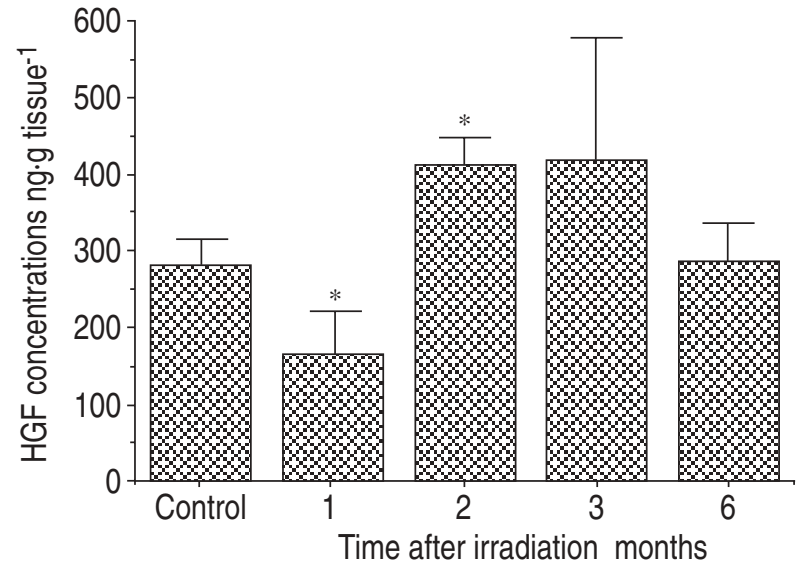

Fig. 1. - Changes of hepatocyte growth factor (HGF) protein levels in lung of rats after whole thoracic irradiation. Value are presented as mean $\pm S D$ of triplicate experiments, conducted on five rats per group (four rats at 2 months, three rats at 3 and 6 months). *: p<0.05 compared to control value.

control was $280 \pm 35 \mathrm{ng} \cdot \mathrm{g}$ tissue ${ }^{-1}$. A decrease in the HGF protein level was observed 1 month after thoracic irradiation $\left(165 \pm 54 \mathrm{ng} \cdot \mathrm{g}\right.$ tissue $\left.{ }^{-1}, \mathrm{p}<0.05\right)$, after which the HGF protein level increased $2\left(410 \pm 35 \mathrm{ng} \cdot \mathrm{g}\right.$ tissue $\mathrm{e}^{-1}, \mathrm{p}<$ $0.05)$ and 3 months subsequent to treatment $(415 \pm 160$ ng.g tissue ${ }^{-1}$, nonsignificant), to a level 1.4 times higher than the baseline value in rat lung. HGF protein concentration in plasma was also measured at the same intervals after thoracic irradiation. It remained below estimated levels (less than $0.2 \mathrm{ng} \cdot \mathrm{mL}^{-1}$ ) throughout the examined period of examination after thoracic irradiation. In the group examined 2 months later, one rat had died before the examination. Pleural effusion was found in two of five rats in the group examined 2 months after irradiation. Two rats had died by the third month after treatment while two rats had died in the group examined 6 months later.

\section{Analysis of BALF and serum HGF in patients}

Table 2 shows an outline of the data obtained for BALF. The number of cells, percentage of lymphocytes,

Table 2. - Comparison of substances in the bronchoalveolar lavage fluid of irradiated and control areas

\begin{tabular}{lccc}
\hline & $\begin{array}{c}\text { Irradiated } \\
\text { area } \\
(\mathrm{n}=11)\end{array}$ & $\begin{array}{c}\text { Control } \\
\text { area } \\
(\mathrm{n}=11)\end{array}$ & $\mathrm{p}$-value \\
\hline Cell number cells·mL-1 & $128 \pm 94$ & $118 \pm 76$ & $\mathrm{NS}$ \\
Macrophage \% & $60 \pm 24$ & $67 \pm 26$ & $\mathrm{NS}$ \\
Lymphocyte \% & $32 \pm 25$ & $29 \pm 26$ & $\mathrm{NS}$ \\
Neutrophil \% & $6.45 \pm 9.2$ & $3.3 \pm 4.9$ & $\mathrm{NS}$ \\
Eosinophil \% & $1.8 \pm 2.7$ & $0.26 \pm 0.4$ & $\mathrm{NS}(\mathrm{p}=0.07)$ \\
Total protein $\mathrm{mg} \cdot \mathrm{dL}^{-1}$ & $31 \pm 29$ & $24 \pm 23$ & $\mathrm{NS}$ \\
Albumin mg.dL-1 & $15.4 \pm 15$ & $11 \pm 10$ & $\mathrm{NS}$ \\
HGF ng.mL-1 & $0.3 \pm 0.4$ & $1.1 \pm 1.2$ & $\mathrm{p}<0.05$ \\
HGF/Albumin $\mathrm{ng} \cdot \mathrm{mg}^{-1}$ & $0.17 \pm 0.2$ & $1.9 \pm 2.5$ & $\mathrm{NS}$ \\
PIIIP U·mL-1 & $0.48 \pm 0.65$ & $0.27 \pm 0.21$ & $\mathrm{NS}$ \\
CD4 \% & $27 \pm 17$ & $24 \pm 18$ & $\mathrm{NS}$ \\
CD8 \% & $28 \pm 17$ & $22 \pm 15$ & $\mathrm{NS}$ \\
CD4/CD8 & $0.84 \pm 0.48$ & $0.93 \pm 0.57$ & $\mathrm{NS}$ \\
CD25 \% & $5.4 \pm 4.9$ & $6.0 \pm 6.6$ & $\mathrm{NS}$ \\
Interleukin-6 $\mathrm{pg} \cdot \mathrm{mL}^{-1}$ & $35 \pm 45$ & $68 \pm 108$ & $\mathrm{NS}$ \\
\hline
\end{tabular}

HGF: hepatocyte growth factor; PIIIP: aminoterminal peptide of type III precollagen. Ns: nonsignificant. 


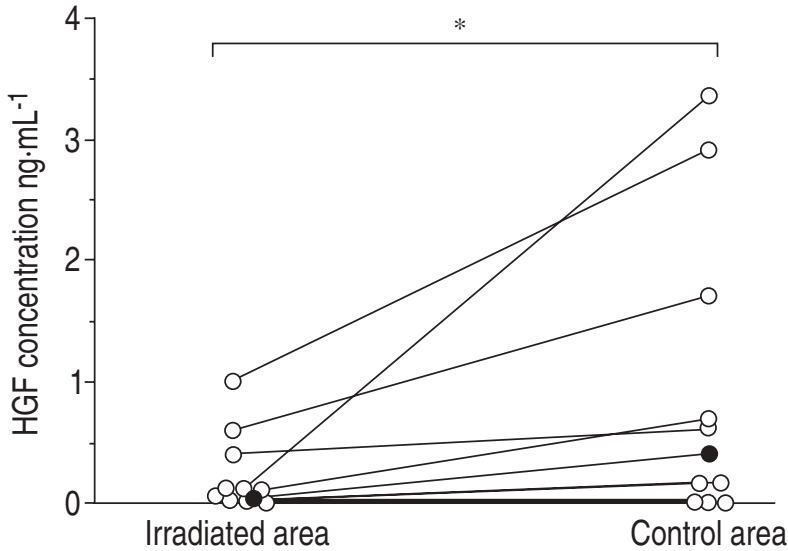

Fig. 2. - Hepatocyte growth factor (HGF) protein levels in the bronchoalveolar lavage fluid of 11 patients after completion of radiation therapy. : patients who showed clinical symptoms of radiation pneumonia. *: $\mathrm{p}<0.05$.

protein and albumin concentrations, and PIIIP and CD4/CD8 ratios showed no significant differences between the irradiated and control areas. The HGF protein level in the irradiated area, however, showed a lower value $\left(0.3 \pm 0.4 \mathrm{ng} \cdot \mathrm{mL}^{-1}\right)$ compared to that of the control area value $\left(1.1 \pm 1.2 \mathrm{ng} \cdot \mathrm{mL}^{-1}, \mathrm{p}<0.05\right)$. Individual values of HGF protein levels are shown in figure 2 . The HGF concentration divided by albumin in the irradiated area was also lower than that of the control area (nonsignificant).

In cellular fractions, the total number of cells increased in both the irradiated and control areas. Percentages of lymphocyte and neutrophils also showed increases in both areas, while slight elevation was seen in the percentage of eosinophils in the irradiated area (nonsignificant). Total protein and albumin increased in both areas compared to normal control values, but the percentages of CD4, CD8, and CD25 showed no change in this analysis. For PIIIP and IL-6, no significant changes were found between the irradiated and control areas. However, levels of these two entities seemed to be higher than normal values, but we did not have access to a well-established normal range for PIIIP and IL-6. Finally, analysis of serum HGF showed no significant changes after irradiation (fig. 3).

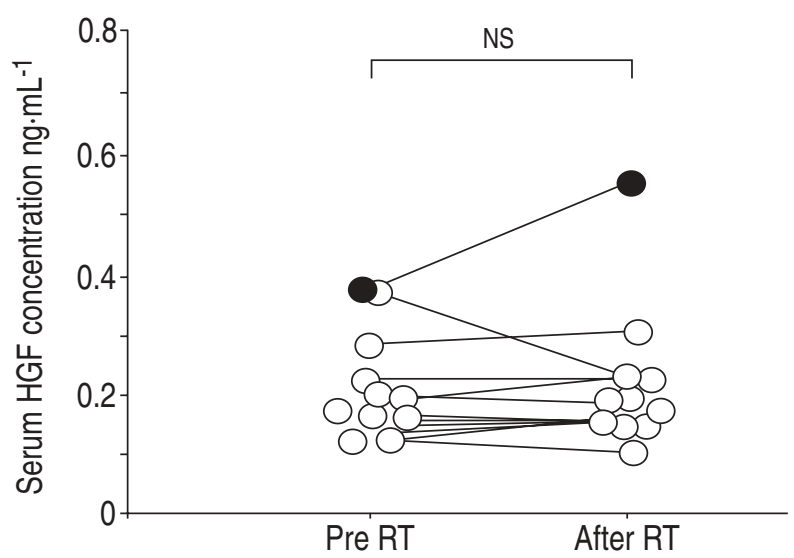

Fig. 3. - Changes of serum hepatocyte growth factor (HGF) protein levels in 11 patients before and after radiation therapy. $\bullet$ : patients who showed clinical symptoms of radiation pneumonia. Ns: nonsignificant.
Table 3. - Outcome of patients treated with radiation therapy

\begin{tabular}{cccccc}
\hline $\begin{array}{c}\text { Patient } \\
\text { No. }\end{array}$ & $\begin{array}{c}\text { Outcome } \\
\text { of } \\
\text { treatment }\end{array}$ & $\begin{array}{c}\text { Duration } \\
\text { after } \\
\text { treatment }\end{array}$ & $\begin{array}{c}\text { Alive/ } \\
\text { Dead }\end{array}$ & \multicolumn{2}{c}{$\begin{array}{c}\text { Radiation } \\
\text { pneumonitis }\end{array}$} \\
\cline { 5 - 6 } & & & & CT & Clinical \\
\hline 2 & CR & 28 & Alive & + & - \\
3 & NC & 18 & Dead & + & - \\
4 & PR & 9 & Dead & + & + \\
5 & PR & 24 & Dead & - & - \\
6 & PR & 11 & Alive & + & - \\
7 & PR & 5 & Dead & + & - \\
8 & NC & 3 & Alive & + & - \\
9 & PR & 4 & Alive & + & - \\
10 & MR & 15 & Dead & + & - \\
11 & PR & 8 & Dead & + & - \\
\hline
\end{tabular}

CT: computed tomography; CR: complete response; PR: partial response; NC: no change; MR: minor response.

\section{Radiation pneumonitis in patients}

Almost all patients showed abnormal shadows on follow-up CT scans (table 3), although clinical radiation pneumonitis appeared in only one patient (patient 3) 2 months after completion of radiation therapy (table 2 , fig. 2), and was successfully treated. The patient showed a slightly higher level of serum HGF, $0.4 \mathrm{ng} \cdot \mathrm{mL}^{-1}$ before and $0.6 \mathrm{ng} \cdot \mathrm{mL}^{-1}$ after radiation therapy.

\section{Discussion}

This study showed that HGF protein level decreased after 1 month and increased 2 and 3 months after thoracic irradiation in rats accompanied by clinical symptoms of radiation pneumonia such as pleural effusion and infiltration of inflammatory cells seen on photomicrographs (data not shown). Inflammation inducible cytokines such as IL-6 and interferon, which are reported to be inducers of HGF, are also induced by irradiation stimulation $[25,26]$. Thus, these multiple cytokines supposedly introduce elevated HGF expressions concurrently with inflammation. HGF reverted to baseline value 6 months after irradiation, concurrent with the disappearance of other symptomatic changes. As serum HGF in patients with lung diseases is reportedly higher [22], HGF is also thought to be one of the inflammation inducing cytokines in human lung. In fact, as HGF production is regulated by multiple factors, we think that these changes do not represent a direct induction of HGF by irradiation, but are the result of indirect and complicated pathways involving radiation lung injury.

As BALF represents one of the most sensitive indicators of local lung physiological changes, we carried out BAL to obtain the BALF from 11 patients just after radiation therapy. We could not detect any difference in the components between the irradiated and nonirradiated areas, except for HGF. An increase in the number of cells as well as elevation of protein and albumin levels in BALF were recognized in both irradiated and control areas. Elevation of cell counts in BALF accompanied by an increase in the number of lymphocytes, 
concurrent with permeability oedema and release of collagenolytic enzymes after irradiation, is a well documented phenomenon [27]. IL-6 may also increase in both areas. These intrapulmonary diffuse changes seem to represent a previously existing basic inflammatory reaction induced by several factors, i.e. chemotherapy and/or malignancies.

In patients with thoracic malignancies after radiation therapy, BALF in the irradiated lung showed a decrease of HGF concentration, while decreasing HGF protein level in rat lung 1 month after irradiation seemed to support the result obtained for BALF. From this evidence, we assumed that HGF production was transitionally suppressed after irradiation. RUBIN et al. [28] cited transforming growth factor $\beta$ (TGF $\beta$ ) as one of the mainstays of radiation induced lung injury which was found to increase just after irradiation, accompanied by a change in permeability and fibrosis. In addition, Matsumoto et al. [8] reported that TGF $\beta$ suppresses HGF production in cell culture. Thus, in addition to the direct damage to HGF production cells by irradiation, TGF $\beta$ has the potential to suppress HGF expression after irradiation.

Several limitations of this study need to be considered. First, we assessed HGF levels in BALF at only one time point, so that the time course of post-irradiation HGF changes in BALF could not be assessed. Secondly, as only one patient showed clinical radiation pneumonitis, it could not be established whether HGF correlated with radiation pneumonitis.

HGF is not only a strong mitogen and motogen as a result of regeneration, but also a cytokine having potential cytoprotection as reported in liver and kidney [15, 16]. If HGF can prevent radiation lung injury, HGF may have the potential to be used for that purpose. However, this concept needs further examination and study.

In summary, hepatocyte growth factor in irradiated lung, as evidenced in the bronchoalveolar lavage fluid of patients with thoracic malignancies, showed lower levels than in nonirradiated areas after completion of radiation therapy. In rat, hepatocyte growth factor protein level in lung tissue decreased 1 month after total thoracic irradiation, showed elevation 2-3 months afterward, and returned to previous values 6 months after thoracic irradiation.

Acknowledgements: The authors would like to thank T. Nakamura and K. Matsumoto for critical discussion and material support.

\section{References}

1. Nakamura T, Nawa K, Ichihara A, Kaise N, Nishimoto T. Purification and subunit structure of hepatocyte growth factor from rat platelet. FEBS Lett 1987; 224: 311-316.

2. Gohda E, Tsubouchi H, Nakayama $\mathrm{H}$, et al. Purification and partial characterization of hepatocyte growth factor from plasma of a fulminant hepatic failure. J Clin Invest 1988; 81: 414-419.

3. Zarnegar R, Michalopoulos GK. Purification and biological characterization of human hepatopoietin A, a polypeptide growth factor for hepatocyte. Cancer Res 1989; 49: 3314-3320.
4. Nakamura T, Nishizawa T, Hagiya M, et al. Molecular cloning and expression of human hepatocyte growth factor. Nature 1989; 342: 440-443.

5. Miyazawa K, Tsubouchi H, Naka D, et al. Molecular cloning and sequence analysis of cDNA for human hepatocyte growth factor. Biochem Biophys Res Commun 1989; 163: 967-973.

6. Noji S, Tashiro K, Koyama E, et al. Expression of hepatocyte growth factor gene in endothelial and Kupffer cells of damaged rat liver, as revealed by in situ hybridization. Biochem Biophys Res Commun 1991; 1734: 42-47.

7. Schirmacher P, Greet A, Jung W, Pietrangelo A, Rogler $\mathrm{CE}$, Dienes HP. The role of Ito cells in the biosynthesis of HGF-SF in the liver. EXS 1993; 65: 285-299.

8. Matsumoto K, Nakamura T. Meiotropic role of HGF in mitogenesis and organ regeneration. Gann Monograph on Cancer Research 1994; 42: 91-112.

9. Okajima A, Miyazawa K, Kitamura N. Primary structure of rat hepatocyte growth factor and induction of its mRNA during liver regeneration following hepatic injury. Eur J Biochem 1990; 193: 375-381.

10. Hamanoue M, Kawaida K, Takao S, et al. Rapid and marked induction of hepatocyte growth factor during liver regeneration after ischemic or crush injury. Hepatology 1992; 16: 1485-1492.

11. Zarnegar R, DeFrances MC, Kost DP, Lindroos P, Michalopoulos GK. Expression of hepatocyte growth factor mRNA in regenerating rat liver after partial hepatectomy. Biochem Biophys Res Commun 1991; 177: 559-565.

12. Ishiki Y, Ohnishi H, Muto Y, Matsumoto K, Nakamura T. Direct evidence that HGF is a hepatotropic factor for liver generation and has a potent anti-hepatitis effect in vivo. Hepatology 1992; 16: 1227-1235.

13. Lindroos PM, Zarnegar R, Michalopoulos GK. Hepatocyte growth factor (hepatopoietin A) rapidly increases in plasma before DNA synthesis and liver regeneration stimulated by partial hepatectomy and carbon tetrachloride administration. Hepatology 1991; 13: 743-749.

14. Sakon M, Monden M, Gotoh M, et al. Hepatocyte growth factor concentration after liver resection. Lancet 1992; 339: 818.

15. Tani M, Tomiya T, Yamada S, et al. Regulating factors of liver regeneration after hapatectomy. Cancer Chemother Pharmacol 1994; (Suppl) 33: S29-S32.

16. Tsubouchi H, Niitani Y, Hirono S, et al. Levels of human hepatocyte growth factor in serum of patients with various liver diseases determined by an enzymelinked immunosorbent assay. Hepatology 1991; 13: 1-5.

17. Igawa T, Matsumoto K, Kanda S, Saito Y, Nakamura T. Hepatocyte growth factor may function as a renotropic factor for regeneration in rats with acute renal injury. Am J Physiol 1993; 265: F61-68.

18. Kawaida K, Matsumoto K, Shimidzu H, Nakamura T. Hepatocyte growth factor prevents acute renal failure and accelerates renal regeneration in mice. Proc Natl Acad Sci USA 1994; 91: 4357-4361.

19. Miller SB, Martin DR, Kissane J, Hammerman MR. Hepatocyte growth factor accelerates recovery from acute ischemic renal injury in rats. Am J Physiol 1994; 266: F129-134.

20. Yanagita K, Matsumoto K, Sekiguchi K, Ishibashi H, Niho Y, Nakamura T. Hepatocyte growth factor may act as a pulmotropic factor on lung regeneration after acute lung injury. J Biol Chem 1993; 268: 21212-21217.

21. Oomichi $\mathrm{H}$, Matsumoto $\mathrm{K}$, Nakamura $\mathrm{T}$. In vivo 
mitogenic action of HGF on lung epithelial cells: pulmotrophic role in lung regeneration. Am J Physiol 1996; 270: L1031-1039.

22. Maeda J, Ueki N, Hada T, Higashino K. Elevated serum hepatocyte growth factor/scatter factor levels in inflammatory lung disease. Am J Respir Crit Care Med 1995; 152: 1587-1591.

23. Yamada A, Matsumoto K, Iwanari H, et al. Rapid and sensitive enzyme-linked immunosorbent assay for measurement of HGF in rat and human tissues. Biomed Res 1995; 16: 105-114.

24. Yamazaki H, Tang JT, Inoue Ta, et al. Radiographic changes following radiotherapy in the patients with lung cancer. Strahlenther Oncol 1995; 171: 272-277.

25. Fornance AJ Jr. Mammalian genes induced by radia- tion: activation of genes associated with growth control. Annu Rev Genet 1992; 26: 507-526.

26. Girinsky TA, Pallardy M, Comoy E, et al. Peripheral blood corticotropin-releasing factor, adrenocorticotropic hormone and cytokine (interleukin beta, interleukin-6, tumor necrosis factor alpha) levels after high and low dose total body irradiation in humans. Radiation Research 1994; 139: 360-363.

27. Cordier JF, Mornex JF, Lasne Y, et al. Bronchoalveolar lavage in radiation pneumonitis. Bull Eur Physiopathol Respir 1984; 20: 369-374.

28. Rubin P, Johnston CJ, Williams JP, McDonald S, Finkelstein JN. A perpetual cascade of cytokines postirradiation leads to pulmonary fibrosis. Int J Radiat Oncol Biol Phys 1995; 33: 99-109. 